\title{
LA FERTILIDAD PRÁCTICA DEL PESIMISMO EN SCHOPENHAUER
}

\section{SCHOPENHAUER'S PESSIMISM AND ITS PRACTICAL FERTIITYY}

\author{
Luciana Samamé ${ }^{1}$ \\ Universidad Nacional de Córdoba- CONICET (Argentina)
}

Recibido: 27-2-2015

Aceptado: 1-7-2015

Resumen: Tomando como principal punto de referencia a la filosofía de Schopenhauer, en este trabajo procuraremos evidenciar en qué podría consistir la fertilidad práctica del pesimismo. Si bien el filósofo alemán no postula una doctrina unitaria sobre el mismo, se mostrará de qué manera el pesimismo eudemonista puede reconstruirse como una posición consistente. Asimismo, sugeriremos en qué sentido es este último capaz de contribuir a los debates filosóficos actuales.

Palabras clave: metafísica de la voluntad; sufrimiento; placer; felicidad; sosiego.

\begin{abstract}
In this paper I aim to show the sense in which we can talk about the practical fertility of pessimism. Having this purpose in mind, I will focus on Schopenhauer's Philosophy. Mainly, I will intend to exhibit how eudaimonic pessimism could be consistently reconstructed. I would also like to suggest the contribution the latter is able to make to the current philosophical debate.
\end{abstract}

Key-Words: metaphysics of will; suffering; pleasure; happiness; tranquility.

[1] (lucsamame@yahoo.com.ar) Luciana Samamé es Licenciada y Doctora en Filosofía por la Universidad Nacional de Córdoba (Argentina). Actualmente es becaria posdoctoral del Conicet (Consejo Nacional de Investigaciones Científicas y Técnicas) y su campo de investigación se centra en la ética de las virtudes. Es miembro del programa "Derecho, Ética y Política» y forma parte del proyecto de investigación «La evaluación moral de las instituciones públicas. Hacia una sociedad democrática de ciudadanos libres e iguales» (Centro de Investigaciones Jurídicas y Sociales/Universidad Nacional de Córdoba) 


\section{Introducción}

Tras el giro aretaico que la teoría ética emprende hacia finales de los años cincuenta -viraje que, por lo demás, no ha cesado de acentuarse y expandirse-, una serie de cuestiones vuelven a capturar la atención filosófica. Entre ellas, cuáles son las virtudes o excelencias morales conducentes a una vida floreciente y buena, o en términos más acotados, a una vida satisfactoria en su conjunto. En este contexto, se reanuda con fuerza la tematización de la felicidad: al igual que los filósofos eudemonistas de la Antigüedad, los teóricos contemporáneos sospechan que la moralidad no puede estar divorciada, después de todo, de la felicidad. Basta echar una mirada a la literatura filosófica reciente para cerciorarse de la importancia que dicho tópico viene exhibiendo desde hace ya algunas décadas ${ }^{2}$, especialmente en el mundo angloparlante -mundo en el que se acogió con mayor entusiasmo el resurgimiento de las éticas de la virtud-.

Acabamos de referir un escenario en el que vuelve a reconocerse la decisiva importancia del bienestar personal para nuestro desarrollo en cuanto agentes morales. Teniendo en cuenta este conjunto de preocupaciones filosóficas actuales, nos parece que vale la pena presentar aquí algunas sugerentes y valiosas ideas de alguien que pensó a fondo dicha cuestión: nos referimos a Schopenhauer, conocido sobre todo y paradójicamente, por su pesimismo. Como veremos, este último presenta una conexión especial con la cuestión de la felicidad. Aunque esta conexión pueda sugerir prima facie la esterilidad que el pesimismo envuelve desde un punto de vista práctico, veremos que está, por el contrario, imbuido de potencialidad. De ahí que se haya escogido la expresión "fertilidad práctica» para referir ese aspecto.

Ahora bien, es difícil precisar con exactitud el sentido que tiene el pesimismo en Schopenhauer en cuanto doctrina filosófica. ${ }^{3} \mathrm{Al}$ respecto, las divergencias interpretativas cubren un amplísimo espectro: desde quienes se niegan a leer su filosofía en clave pesimista ${ }^{4}$, hasta aquellos

[2] Por mencionar solamente algunos títulos: «The Morality of Happiness» de Julia Annas (1993); "Wellfare, Happiness, and Ethics» de L. Sumner (1996); "Well-Being and Morality» de R. Crisp and Hooker (eds) (2000); "What is Good and Why: the Ethics of Well-being" de Richard Kraut (2009); «The Good Life» de Michael Bishop (2014).

[3] Damos aquí por sentada la distinción entre pesimismo en cuanto rasgo psicológico -el de la persona que tiende a ver siempre el lado negativo de las cosas- y el pesimismo en cuanto sistema filosófico.

[4] El representante paradigmático de esta posición es Brian Magee, y en menor medida también, Hamlyn y Gardiner. El primero es famoso por sostener que «filosofía» y "pesimismo» constituyen términos lógicamente independientes, razón por la cual se ve llevado a concluir que «el estudio de su pensamiento [el de Schopenhauer] desde el punto de vista de su pesimismo es irrelevante para una consideración seria de su obra desde una perspectiva filosófica». Magee, B.: Schopenhauer. Madrid: Cátedra, 1991, p. 20.

Thémata. Revista de Filosofía No53 (2016) pp.: 141-160. 
que asocian su pesimismo con diferentes elementos de su sistema. En esta dirección, por ejemplo, se ha dicho que Schopenhauer es pesimista porque: 1) niega la inmortalidad del alma y un significado último a la existencia; 2) identifica lo real con un impulso ateleológico e irracional; 3) se opone a la idea de progreso moral, tanto individual como colectivo; 4) defiende el determinismo y la inalterabilidad del carácter; 5) postula una concepción de naturaleza humana bastante desalentadora, donde el egoísmo y la maldad son sus rasgos prevalecientes; 6) sostiene que la condición humana es esencialmente desventurada, siendo sus chances de felicidad bastante estrechas. ${ }^{5}$ Por razones obvias, es este último sentido el que nos interesa explorar aquí.

Más allá de estos matices interpretativos, existe amplio consenso sobre el hecho de que el pesimismo schopenhaueriano se enraíza en su metafísica de la voluntad y que de ello se desprenden decisivas implicancias para la vida humana y sus perspectivas de felicidad. Como decía Thomas Mann: Schopenhauer es el filósofo del pesimismo por ser el filósofo de la voluntad, puesto que al ser esta última lo contrario a una satisfacción en reposo, se trata en sí misma de algo fundamentalmente desdichado. ${ }^{6} \mathrm{Si}$ guiendo esta pista, John Atwell sostiene que el pesimismo schopenhaueriano está referido a la felicidad terrena. ${ }^{7}$

Atendiendo al entramado de aspectos señalados, este trabajo exhibirá la siguiente estructura: en primer lugar, se hará una alusión a la condición humana tal como Schopenhauer la concibe en el marco de su metafísica de la voluntad; luego se abordará su concepción de felicidad y los argumentos defectuosos y confusos en los que basa su pesimismo; finalmente -siendo éste el principal objetivo que nos anima-, se intentará mostrar que a pesar de tales flaquezas teórico-argumentativas, el pesimismo se puede reconstruir como una posición consistente, radicando su riqueza fundamental en su potencial práctico, en su capacidad de orientar nuestras vidas desde una perspectiva de conjunto. En resumidas cuentas, el "pesimismo eudemonista» proporciona una respuesta plausible a la cuestión práctica fundamental, a saber: «¿cómo debe uno vivir?» ${ }^{8}$

[5] Cf. Atwell, J.: Schopenhauer. The Human Character. Philadelphia: Temple University Press, 1990, pp. 150-155.

[6] Cf. Mann, T.: Schopenhauer, Nietzsche, Freud. Madrid: Alianza Editorial, 2000, pp. 32-33.

[7] Cf. Atwell, op. cit., p. 175.

[8] Platón: República, 352 d.

Thémata. Revista de Filosofía $\mathrm{N}^{\circ} 53$ (2016) pp.: 141-160. 


\section{De la condición humana y la felicidad (im)posible}

\section{1. "Alles Leben Leiden ist»}

Quizá nuestro mejor punto de arranque sea la caracterización schopenhaueriana de la vida humana, profundamente enraizada en su metafísica de la voluntad. Partiendo de la distinción kantiana entre fenómeno y noúmeno, Schopenhauer aborda este último a partir del concepto de «voluntad» (Wille), a la que entiende como un impulso ciego y una aspiración sin fin. Sobre esta concepción se modelan decisivas consideraciones sobre la condición humana:

El eterno devenir, el flujo sin fin corresponde a la manifestación de la esencia de la voluntad. Eso mismo se muestra también en los anhelos y deseos humanos, que nos engañan al presentar su consumación como la última meta del querer; mas tan pronto como son alcanzados, dejan de verse así y pronto se olvidan como algo anticuado, dejándolos a un lado como engaños que se han disipado. ${ }^{9}$

En cuanto manifestación fenoménica de la voluntad, la vida de cada individuo presenta este singular rasgo: su transcurso vital suele consumirse en el continuo esfuerzo por alcanzar alguna cosa, pero tan pronto es ésta alcanzada, vuelve a presentarse en su lugar un nuevo anhelo. Ello obedece, íntimamente, a que cada deseo configura una expresión particularizada de esa aspiración sin fin que constituye a la voluntad. Sobre la base de tal caracterización metafísica, Schopenhauer asienta su visión antropológica: el ser humano es, prioritariamente, un sujeto volitivo tironeado por una legión de deseos. De esto se desprende que la nota fundamental de la existencia es la del dolor, pues «al no darse ningún objetivo final de la tendencia, no hay tampoco medida ni término del sufrimiento». ${ }^{10}$ Es así como nuestro autor se ve llevado a proclamar que el dolor es consubstancial a la vida (alles Leben Leiden ist). ${ }^{11}$ Esta conclusión se basa en el siguiente

[9] Schopenhauer, A.: El Mundo como Voluntad y Representación I. Madrid: FCE, 2005, pp. 255-256 (§29) [De ahora en adelante «MVR I»] / W I, 240-241. [En todos los casos, las citas de las obras de Schopenhauer de las ediciones en castellano aquí empleadas, irán acompañadas del número de tomo y página [«W I, 240»] con los que se corresponden respecto de la siguiente edición crítica de sus obras completas: Schopenhauer, A: Sämtliche Werke. Stuttgart/Frankfurt am Main: Cotta-Insel, 1960-1965 (5 vols.)].

[10] MVR I, p. 405 (§56) / W I, 425.

[11] Cf. MVR I, p. 406 (§56) / W I, 426. La sensibilidad para el dolor será más grande cuanto mayor sea el grado de inteligencia. Ciertamente, lo que Schopenhauer quiere establecer es que el dolor es consubstancial a la vida humana, ya que «la capacidad deliberativa del hombre es una de las cosas que hacen a su existencia mucho más atormentada que la del animal,

Thémata. Revista de Filosofía №53 (2016) pp.: 141-160. 
razonamiento: todo querer (Wollen) presupone una carencia (Mangel), y la carencia, dolor (Leiden). ${ }^{12}$

Schopenhauer cree que la vida humana transcurre generalmente de esta forma: procurando, en el nivel más básico, lo necesario para el sustento propio y el de la prole, pero persiguiendo, además, cualquier tipo de meta que ocasionalmente se le presenta. "Trabajo, molestia, cansancio y necesidad constituyen desde luego, a lo largo de toda su vida, la suerte de casi todos los hombres». ${ }^{13}$ Ahora bien, ¿qué pasaría si una persona consiguiera sustraerse de la necesidad, por ser capaz de satisfacer cualquier deseo con toda prontitud y facilidad? A juicio de Schopenhauer, quedaría expuesta ante una amenaza no menos temible, la del aburrimiento (Langeweile):

Originariamente el sufrimiento es carencia, menesterosidad, preocupación por el mantenimiento de la vida... Si finalmente no puede tener entrada bajo ninguna otra forma, el dolor comparece con el triste y gris ropaje del hastío y el aburrimiento, que se intenta contrarrestar de tan diversas maneras (...) Pues toda vida humana es arrojada de un lado al otro entre el dolor y el aburrimiento. ${ }^{14}$

De esta manera se completa la pintura que representa a la condición humana: ésta se asemeja al movimiento pendular que oscila entre los extremos de dolor y aburrimiento. Si afanarse por algo conlleva dolor, entonces podría pensarse que su contraveneno perfecto residiría, simplemente, en sustraer la voluntad individual de todo motivo. Pero aquí Schopenhauer nos sorprende al argumentar que cuando a la voluntad le falta un objeto, ella se transforma en un «lánguido anhelo», en un «mortífero abatimiento» donde la vida se petrifica. ${ }^{15}$

Lo precedente podría reformularse en los siguientes términos: la persona que está aburrida se encuentra sumida en un estado de dolor, porque si bien ningún cuidado le preocupa, ningún deseo demanda su satisfacción, esta persona desearía, con todo, poseer algún deseo. Desde la óptica

pues en general nuestros mayores dolores no están en el presente, sino que se hallan en la razón, como conceptos abstractos y pensamientos aflictivos de los que sólo el animal está libre, al vivir en el presente y en una envidiable despreocupación». MVR I, p. 393 (§55) / W I, 410.

[12] Cf. MVR I, p. 287 (§38) / W I, 279.

[13] Schopenhauer, A.: Parerga y Paralipomena II. Madrid: Trotta, 2009, p. 309 (§152) [De ahora en adelante «PP II»] / W V, 345.

[14] MVR I, p. 411 (§57) / W I, 432.

[15] Cf. MVR I, p. 256 (§29) / W I, 241. En la medida en que el ser humano es voluntad, su esencia se realiza haciendo antes que siendo. Por eso la falta de un objeto que lo ponga en movimiento, representa un problema para un ser de tal naturaleza.

Thémata. Revista de Filosofía No53 (2016) pp.: 141-160. 
schopenhaueriana, luego, quien está aburrido posee un deseo de segundo grado: desea desear. ${ }^{16}$ En semejante disposición anímica, si bien ningún estado de cosas en el mundo desea alcanzarse, persiste, paradójicamente, el deseo de ser motivado por algún estado de cosas. Consiguientemente, el aburrimiento constituye también una experiencia profundamente insatisfactoria, porque quien cae presa del mismo, continúa padeciendo la presión de la voluntad. Y según ha establecido Schopenhauer, todo querer, cualquiera sea la forma bajo la que se presente, arrastra necesariamente consigo alguna especie de penalidad. A este posicionamiento, Jordi Fernandez ha denominado muy acertadamente "pesimismo condicional»: en la medida en que deseamos, el sufrimiento es inevitable. ${ }^{17}$

\subsection{El punto de vista hedonista}

Si la vida humana oscila de continuo entre los polos de dolor y aburrimiento, entonces parece quedar firme la sentencia según la cual el sufrimiento resulta consustancial a la vida. En este escenario, bastante sombrío y desesperanzador, las probabilidades de hacer sitio a la felicidad amenazan reducirse, prácticamente, a cero. A ello apuntan, en efecto, ciertas aseveraciones que Schopenhauer hace: que la vida humana no es, según sus disposiciones, susceptible de ninguna felicidad verdadera ${ }^{18}$; que nadie hasta el presente se ha sentido completamente feliz, a no ser que estuviese ebrio ${ }^{19}$; que no existe error más palmario que el de suponer que la vida existe para ser disfrutada y el ser humano, para ser feliz. ${ }^{20}$ Para

[16] Cf. Young, J.: Schopenhauer. New York: Routledge, 2005, p. 211.

[17] Esta forma de pesimismo condicional debe distinguirse debidamente de un pesimismo absoluto: este último sería incompatible con la posibilidad de redención que la filosofía schopenhaueriana admite mediante la negación de la voluntad. Cf. Fernandez, J.: «Schopenhauer's Pessimism» en Philosophy and Phenomenological Research, Vol. LXIII N ${ }^{\circ}$ 3, 2006, p. 648.

[18] Cf. MVR I, p. 420 (§59) / W I, 443.

[19] Cf. PP II, p. 303 (§146) / W V, 339.

[20] Cf. MVR II, p. 555 / W II, 734. En esta misma línea se ubica su afirmación de que solamente existe un error innato (angeborenen Irrtum), consistente en creer que nacemos para ser felices (Cf. MVR II, p. 616 / W II, 813). Aquí confluyen dos ideas importantes. En primer lugar, el señalamiento de un error en nuestro juicio, el de creer que podemos ser felices mediante la «satisfacción sucesiva de todo nuestro querer». En segundo lugar, la inexactitud de cifrar el fin humano en la felicidad: Schopenhauer, al igual que Kant, estipula que el fin de la existencia es moral. Cf. MVR II, p. 228 / W II, 302.

Thémata. Revista de Filosofía №53 (2016) pp.: 141-160. 
examinar el alcance de semejantes palabras se vuelve perentorio dilucidar qué concepción de felicidad tiene Schopenhauer en mente al proferirlas.

Cada vez que ensaya una definición, nos confronta con un concepto de felicidad (Glück) marcadamente hedonista. Así lo reflejan los siguientes pasajes:

(...) la sucesiva satisfacción [Befriedigung] de todo nuestro querer es lo que se piensa mediante el concepto de felicidad. ${ }^{21}$

Como la esencia del hombre consiste en que su voluntad anhela, se satisface y anhela de nuevo, y así continuamente, su dicha [Glück] y bienestar [Wohlsein] se reducen a que ese tránsito del deseo hacia la satisfacción y de ésta hacia un nuevo deseo avance rápidamente... ${ }^{22}$

Por muy variadas que sean las formas bajo las que la felicidad o infelicidad del hombre se presenta y le mueve a la persecución o la huida, la base material de todas ellas es el placer o dolor corporales. ${ }^{23}$

En estas especificaciones, los conceptos de «satisfacción» (Befriedigung), «deseo» (Wunsch), «placer» (Genuß) y su contrario «dolor» (Sch$m e r z)$, desempeñan roles estelares. Ahora bien, el placer parece depender prioritariamente de la satisfacción de deseos, en tanto el dolor, de su no-satisfacción u obstaculización. Ello implica presumiblemente que la felicidad es la condición en la que todos nuestros deseos encontrarían cumplimiento y en donde se experimentaría un placer permanente. Schopenhauer coloca así muy alto -como dice Jordi Fernandez- la vara de la felicidad. ${ }^{24}$ Luego cuando declara su imposibilidad, simplemente quiere decir que seríamos incapaces de experimentar placer en forma ininterrumpida, ya que no hay modo de satisfacer perdurablemente a la voluntad. Para demostrarlo, Schopenhauer se vale de una serie de argumentos, algunos de índole empírica, otros de naturaleza conceptual.

La primera observación, quizá la más obvia, es que la pretensión de satisfacer todos nuestros deseos se ve a menudo desbancada por la forma en que transcurren los hechos: el mundo no suele corresponderse con nuestros anhelos. ${ }^{25}$ La satisfacción ininterrumpida de nuestro querer es prácticamente imposible dado que, por un lado, es altamente probable que entre el deseo y su cumplimiento se interponga algún obstáculo, o incluso,

[21] MVR II, p. 616 / / W II, 813. [El énfasis es nuestro]

[22] MVR I, p. 353 (\$52) / W I, 362. [El énfasis es nuestro]

[23] PP II, p. 309 (\$152) / W V, 345. [El énfasis es nuestro]

[24] Fernandez, J.: op. cit., p. 651.

[25] Cf. MVR II, p. 618 / W II, 816.

Thémata. Revista de Filosofía $\mathrm{N}^{\circ} 53$ (2016) pp.: 141-160. 
su descompasamiento. A veces el logro de un propósito llega demasiado tarde, cuando su añoranza ya ha desaparecido, lo que nos vuelve ineptos para su disfrute. ${ }^{26}$ Por otro lado, la satisfacción sucesiva de nuestro querer resultaría inviable aún cuando se lograra tal cometido. Esto es lo que desea demostrarse a partir del argumento del aburrimiento. Hasta la persona "exitosa», es decir, alguien que consigue concretar a cada paso sus deseos, seguiría expuesta al sufrimiento al ser capturada por el deseo de poseer un deseo. En conclusión: tanto quien fracasa en cumplir sus propósitos como quien los alcanza fácilmente, se encuentra por igual en una condición desdichada. La enseñanza que Schopenhauer quiere proporcionar con todo esto es manifiesta: mientras deseamos, estamos condenados a habitar un mundo de insatisfacción permanente. ${ }^{27}$

De lo precedente se desprende la inviabilidad de colmar sucesivamente a la voluntad. A esto hay que agregar la imposibilidad de complacerla en forma perdurable. Para ello dispone nuestro autor de un argumento conceptual: la voluntad es, por definición, aspiración sin fin; lo cual excluye lógicamente la posibilidad de pensarla como algo que pueda ser definitivamente saciado. ${ }^{28}$ En este punto es donde Mann veía fraguarse el pesimismo schopenhaueriano. Recordemos sus palabras según las cuales Schopenhauer es el filósofo del pesimismo por ser el filósofo de la voluntad -lo contrario a una satisfacción en reposo-.

\subsection{La negatividad del placer y la felicidad}

A los argumentos precedentes hay que añadir una tesis de suma importancia, la de la negatividad de la felicidad. Algunos autores ven en ella una pieza esencial del pesimismo schopenhaueriano. ${ }^{29} \mathrm{~A}$ juicio del filósofo de la voluntad:

[26] Cf. Schopenhauer, A.: Parerga y Paralipomena I. Madrid: Trotta, 2006, p. 427 [De ahora en adelante «PP I»] / W IV , 491.

[27] En consecuencia, o suprimimos nuestros deseos o los reducimos considerablemente de cara a nuestro sosiego.

[28] Así, para Schopenhauer, la proposición que reza "el dolor es consustancial a la vida» puede ser establecida a priori (Cf. MVR I, p. 420 (§59) / W I, 443), una vez reconocida la voluntad como en-sí de todo fenómeno. A partir de la caracterización de esta última en cuanto «tendencia sin objetivo ni final alguno», la idea de su irremediable destino de insatisfacción perdurable, se desprende en calidad de corolario indefectible.

[29] Cf. Janaway, C.: «Schopenhauer's Pessimism» en Janaway C. (ed): The Cambridge Companion to Schopenhauer. Cambridge: Cambridge University Press, 2006, p. 332.

Thémata. Revista de Filosofía No53 (2016) pp.: 141-160. 
Toda satisfacción, o lo que comúnmente se llama dicha, sólo es siempre estricta y esencialmente negativa y, por ende, nunca es positiva. La felicidad no es algo que nos ocurra originariamente y por sí mismo... Por eso la satisfacción o la felicidad nunca puede ser más que la liberación de un dolor, de una necesidad $(. . .)^{30}$

¿Cómo entender esta presunta negatividad? Schopenhauer parece querer decir dos cosas: por un lado, que la experiencia del placer es tan breve, que se vuelve casi imperceptible; por el otro, que su sustancia no es otra que la supresión de un dolor. Si unimos estas dos ideas, entonces daremos con que el goce, la satisfacción o la felicidad, pueden identificarse en tal sentido con una sensación de alivio, desahogo o sosiego. Esta concepción, por su parte, posee una larga historia y se remonta a la tradición epicúrea. ${ }^{31}$

El autor de El mundo como voluntad y representación se propone argüir, en suma, la negatividad del placer, nuestra incapacidad de experimentarlo en forma positiva. "Negatividad» aludiría así a una condición en la que algo solamente puede ser conocido en forma mediata o indirecta (mittelbar erkennen). Para apoyar esta tesis, Schopenhauer ofrece una serie de consideraciones de resonancia psicológica. Si prestamos atención a aquello experimentado tras consumarse un deseo, se observará lo siguiente: que la satisfacción alcanzada no complace tanto como prometía, por lo que solemos sentirnos estafados; que la posesión quita enseguida el encanto de lo poseído ${ }^{32}$, y que incluso su posesión firme nos lo vuelve im-

[30] MVR I, pp. 415-416 (§58) / W I, 437. [ El énfasis pertenece a Schopenhauer]

[31] En la tradición epicúrea se ha defendido, en efecto, una concepción negativa de felicidad. El mismo Epicuro, quien hermanaba la eudaimonía con un estado placentero, la entendía como ausencia de dolor en el cuerpo y de turbación en el alma. (Ep. Men. 132) Si bien Schopenhauer, a diferencia del «maestro del jardín», no está dispuesto a aceptar el emparejamiento del bien supremo con el placer, renegando en tal dirección del hedonismo, la influencia de esta tradición sobre su pensamiento parece ser mayor de lo que él mismo está dispuesto a reconocer. De lo contrario, ¿cómo explicar que en pasajes fundamentales de su obra, donde se empuña una concepción negativa de felicidad, el filósofo alemán cite, precisamente, a Lucrecio, un reconocido epicúreo? En la sección 58 de El mundo como voluntad y representación, cuyo asunto central es la exposición y defensa de la negatividad del placer, se hace mención del poeta latino. Este dato no es menor. Si bien no es usual encontrar entre los especialistas de la filosofía schopenhaueriana, referencias a esta filiación con respecto a la tradición epicúrea, G. Else, por ejemplo, un reconocido clasicista, lo señala. En su artículo «Lucretius and the Aesthetic Attitude», de 1930, asevera que pueden encontrarse rastros de Lucrecio en Schopenhauer. Y lo que resulta de central importancia frente a los presentes propósitos: Else sostiene que el filósofo alemán expande la doctrina epicúrea que Lucrecio magistralmente ejemplifica, a saber: que el dolor constituye el hecho positivo, mientras el placer, el negativo.

[32] Cf. MVR I, p. 410 (§57) / W I, 430.

Thémata. Revista de Filosofía No53 (2016) pp.: 141-160. 
perceptible; que tras el advenimiento de una dicha largamente esperada, no nos sentimos, en conjunto y de forma persistente, mejor que antes. ${ }^{33}$

También a esto se anexa una serie de observaciones que podríamos anacrónicamente denominar, de orden fenomenológico. A juicio de Schopenhauer, solamente sentimos en forma inmediata lo desagradable y penoso, proporcionando algunos ejemplos interesantes: que no sentimos la salud de nuestro cuerpo, sino solamente el punto en que nos duele ${ }^{34}$; análogamente, cuando nuestros asuntos marchan bien, no lo percibimos, pero cuando algo va mal lo notamos enseguida. ${ }^{35}$ En la misma línea de razonamiento arguye que, mientras nos hallamos en posesión de los mayores bienes de la vida - a saber, salud, juventud y libertad-, no lo percibimos, volviéndosenos palpables una vez perdidos. ${ }^{36}$ En este contexto, sólo negativamente estaríamos en condiciones de estimarlos: entonces, para poder valorar determinada cosa, sería preciso imaginarnos sin ésta, o comparar nuestra situación con la precariedad sustentada por alguna otra. De esta idea Schopenhauer extraerá un importante presupuesto para su eudemonología: si uno es capaz de reconocer el carácter negativo de la felicidad, tendrá más chances de alcanzarla que aquel otro incapaz de reconocerlo.

\subsection{Objeciones a la tesis de la negatividad de la felicidad}

Las consideraciones precedentes parecen apuntalar la sentencia schopenhaueriana conforme con la cual la vida entraña sufrimiento. Tanto su concepción de voluntad como la tesis de la negatividad de la felicidad explican que «ningún objeto del querer puede, una vez conseguido, procurar una satisfacción duradera y que no se retire jamás». ${ }^{37}$ El problema reside, en definitiva, en aquello que somos: en función de nuestra esencia volitiva estamos inclinados a sufrir, pues en tanto que queremos, necesariamente padecemos. Recordemos que Schopenhauer partía de la idea de que el deseo supone carencia, y ésta, irreparablemente, dolor. Sin embargo, ¿es aceptable esta aseveración? En principio, hay allí implicadas dos proposiciones: la primera, que todo querer surge de una menesterosidad; la segunda, que la falta de aquello que pretendemos, provoca insatisfacción.

Examinemos el primer caso. Todo querer -nos dice Schopenhauersurge de una carencia: sólo podemos afanarnos por aquello que no posee-

[33] Cf. MVR I, p. 412 (§57) / W I, 434.

[34] Cf. PP I, p. 421 / W IV, 483.

[35] Cf. PP II, p. 307 (§149) / W V, 343.

[36] Cf. MVR II, p. 557 / W II, 736.

[37] MVR I, p. 287 (§38) / W I, 279-280.

Thémata. Revista de Filosofía №53 (2016) pp.: 141-160. 
mos. Esta idea no resulta difícil de aceptar, dado que es perfectamente razonable afirmar que la motivación por alcanzar alguna cosa surge como consecuencia de nuestra falta de ella. Por ejemplo, la escasez de empleo en una ciudad populosa, motivaría a buena parte de la población a emigrar a otras ciudades en su busca. La falta de trabajo provocaría el deseo de conseguirlo, incentivando a las personas a realizar las acciones tendientes a ello; en este caso, mudándose de ciudad. El argumento puede incluso llevarse un poco más lejos: supóngase que una de esas personas que migra en busca de empleo, consigue finalmente uno. ¿Esto significa que ya no se esforzará por mantenerlo? Una respuesta perfectamente sensible sería que, efectivamente, esa persona hará lo necesario para conservar su puesto de trabajo, a través de una serie de acciones: llegando cada día puntualmente, respetando las órdenes de su jefe, cumpliendo eficientemente sus tareas, etc. Pero si es posible todavía querer poseer lo que ya posee, ¿significa que Schopenhauer se equivoca al decir que sólo puede quererse lo que no se posee?

Semejante opinión no parece errada, porque inclusive el hecho de que alguien pueda interesarse por conservar lo que ya posee, permite pensarse como un caso de motivación que se origina igualmente en la carencia. ¿No es esto contradictorio? ¿De qué carece alguien que actualmente inviste alguna cosa? Precisamente, de su posesión futura. De esta suerte, quien continúa desvelándose por salvaguardarla, trasluce en su actitud que no la siente como algo seguro. La posibilidad de su pérdida, muy presente ante su vista, ocasiona sus esfuerzos por conservarla. Ello significa, luego, que aun poseyéndose un objeto, hay algo del mismo que no se posee: la garantía de su tenencia permanente. Por tanto, como podríamos eventualmente vernos privados de él, ejecutamos todos los actos que consideramos convenientes para preservarlo. Resulta este un argumento convincente, al menos desde una perspectiva psicológica.

Analicemos ahora la segunda proposición, la que decía que toda carencia conlleva dolor, un estado de profunda insatisfacción. A entender de Young, Schopenhauer comete aquí un error fatal: el de confundir no-satisfacción con insatisfacción. ${ }^{38}$ Para el filósofo de Danzig, el estado de apetencia entraña malestar en la exacta medida en que todavía no ha conseguido su cumplimiento. Sin embargo, de su no-satisfacción no se sigue indefectiblemente para el sujeto que lo experimenta, un estado de insatisfacción. Este punto ha sido señalado también, de manera muy fina, por G. Simmel. ${ }^{39}$

El filósofo y sociólogo alemán sostiene que Schopenhauer basa su tesis de la negatividad de la felicidad en hechos psicológicos. Aunque a

[38] Cf. Young, J.: op. cit., pp. 217-218.

[39] Cf. Simmel, G.: Schopenhauer y Nietzsche. Buenos Aires: Prometeo, 2005, pp. 65-70.

Thémata. Revista de Filosofía №53 (2016) pp.: 141-160. 
su juicio, aquél comprime considerablemente su espectro, reduciéndolos a una lógica binaria: la alternativa exclusiva entre satisfacción y no-satisfacción. En otros términos, Schopenhauer analiza los estados de conciencia solamente desde dos puntos de vista: el de la posesión o cumplimiento del fin, o el de la no-posesión y no-cumplimiento del fin. Mientras el primero estaría atado al placer, el segundo comportaría dolor e insatisfacción. Simmel cree que Schopenhauer se equivoca al menos en dos cosas: en primer lugar, en aplicar un esquema binario que, si bien es de legítima aplicación en ámbitos como la lógica y el derecho, no lo es en absoluto en el territorio psíquico, como si sus únicas disposiciones anímicas se correspondieran siempre con un alterno tener o no-tener; en segundo lugar, el filósofo de Danzig yerra al creer que toda volición involucra dolor.

Simmel argumenta con razón que desde un ángulo psicológico, el placer no se experimenta exclusivamente en el momento de la consecución del fin, sino también en el transcurso de su aproximación al mismo. Hasta puede decirse que esta felicidad anticipada es a veces mayor que aquella experimentada al alcanzarse la meta. Consecuentemente, Schopenhauer podría estar en lo cierto al afirmar que nuestra vida transcurre fundamentalmente a través de procesos volitivos, pero se equivoca al concebirlo como un proceso esencialmente doloroso. El hecho de no encontrarse todavía satisfecha la voluntad, no autoriza inferir su descontento, porque de idéntica premisa podría desprenderse, con igual legitimidad, la posibilidad de su complacencia.

Otra de las críticas dirigidas al posicionamiento schopenhaueriano viene también de la mano de Simmel, la cual presenta una conexión estrecha con la objeción anterior: en su opinión, la tesis de la negatividad de la felicidad es insostenible en vistas del momento positivo que la misma reviste y que Schopenhauer se niega a ver. El argumento en el que Simmel basa ahora su objeción es el siguiente: si la felicidad consistiera simplemente en la liberación del dolor, entonces dicha experiencia no se diferenciaría en sustancia del sueño y de la muerte - dos instancias que se caracterizan también por la cesación del sufrimiento- ${ }^{40} \mathrm{Y}$ ello es algo que puede objetarse al menos desde un punto de vista psicológico, conforme con el cual la significación atribuida a tales estados -la vigilia, el sueño, la muerte- no es equivalente. Desde tal ángulo, la tesis de la negatividad de la felicidad se muestra poco realista, al no representar fidedignamente el modo en que es humanamente vivenciada.

[40] Cf. Simmel, G.: op. cit., p. 72.

Thémata. Revista de Filosofía No53 (2016) pp.: 141-160. 


\section{El pesimismo eudemonista}

Se ha consignado en la introducción que aquí estamos concernidos con uno de los sentidos en que el pesimismo schopenhaueriano ha sido interpretado: en la idea de que el mismo está dirigido a la felicidad terrena, el «bien supremo» a ojos del hombre natural. Podríamos denominarlo, tal como hace Simmel, «pesimismo eudemonista». Schopenhauer, en efecto, asevera que «la felicidad terrenal (irdische Glück) está destinada a desvanecerse o a ser reconocida como una ilusión $»^{41}$, dado que el sesgo dominante de la existencia humana es el dolor. Sin embargo, ¿qué implica este pesimismo respecto de la felicidad humana?: ¿Que no existen en absoluto instancias de placer o felicidad por ser ilusorias?; ¿Que la felicidad ostenta tan sólo un carácter negativo?; ¿Que nadie en el mundo puede ser feliz, o acaso muy pocos?; ¿Que en la vida predominan escandalosamente los dolores sobre los placeres?

Ciertamente, y en relación con la última pregunta, uno de los aspectos en que Schopenhauer basa su apreciación negativa de la vida, reside en la exigüidad de sus placeres:

Antes de asegurar con total confianza que la vida es un bien deseable o digno de gratitud, debiera compararse una sola vez la suma de las posibles alegrías que un hombre puede disfrutar durante su vida con la suma de los posibles sufrimientos que le pueden alcanzar en su vida. Creo que no será difícil de establecer ese balance. ${ }^{42}$

Si se compara, por tanto, la suma de dolores con la de placeres, la balanza se inclinará necesariamente hacia los dolores. Este argumento, por su parte, ha sido objeto de crítica por envolver un fuerte componente hedonista. ${ }^{43}$ El razonamiento que Schopenhauer evidencia seguir es el siguiente: la vida humana contiene esencialmente dolor; por lo tanto, no merece ser vivida. En una versión más completa, podría reformularse así: la vida humana contiene más dolores que placeres, la única cosa digna de valor es el placer; en consecuencia, sería preferible para cada individuo, no existir. Si bien es cierto que desde el punto de vista natural el placer supone el máximo valor, Schopenhauer no lo reconoce en cuanto tal, puesto que admite valores más altos como la virtud y el ascetismo. En consecuencia, este argumento no sería legítimo para fundamentar el pesimismo eudemonista.

Volvamos a una de las tesis medulares de la metafísica de la voluntad: que el sufrimiento es consubstancial a la vida. Es justo preguntarse

[41] MVR II, p. 555 / W II, 734.

[42] MVR II, p. 558 / W II, 737.

[43] Cf. Janaway, C.: op. cit., p. 334. Cf. también Simmel, G.: op. cit., pp. 70-73.

Thémata. Revista de Filosofía №53 (2016) pp.: 141-160. 
si de tal cosa se desprende necesariamente que cada vida individual conlleva, en forma constante, dolor. Al parecer, no estaríamos autorizados a extraer una conclusión tan extrema. Se ha dicho que el Alles Leben Leiden ist se predica en particular de la vida humana, de modo que el sufrimiento pertenece sustancial y no accidentalmente a la esencia de la humanidad. De esta suerte, y por regla general, ocurrirán en la vida humana episodios de dolor. Si bien el sufrimiento es la norma de la vida humana, ello no implica que no puedan existir excepciones por las que alguien consigue sustraerse al dolor. Y de hecho es esta una posibilidad que Schopenhauer admite. ${ }^{44}$

Lo anteriormente argüido nos proporciona la clave para responder una de las preguntas más arriba formulada: la de si Schopenhauer es pesimista por conceder que sólo unos pocos privilegiados podrían gozar de una existencia feliz, esto es, exenta de dolor. Sobre este particular, no nos resulta una razón suficiente para fundar su pesimismo eudemonista. Aristóteles, por ejemplo, pensaba que la eudaimonía era accesible a unos pocos y no por esto se lo considera un pesimista respecto de la felicidad humana.

Analicemos otra de las preguntas más arriba formulada. Cuando Schopenhauer afirma el carácter ilusorio de la felicidad, o que ésta se trata de un error innato, ¿implica acaso que el bienestar que alguien pueda experimentar es ilusorio? Tampoco presume ser ése el caso. En cuanto sujetos volitivos aspiramos siempre hacia alguna meta; como vimos anteriormente, Schopenhauer denomina "sufrimiento» al estado en el que la voluntad no encuentra todavía cumplimiento, en tanto "satisfacción" o «dicha» a la consumación de su objetivo. ${ }^{45}$ Luego, aquél no niega que los episodios de bienestar o satisfacción realmente ocurran, al margen de cuán breves o poco frecuentes puedan ser.

De aquí es posible inferir una significativa conclusión: la ilusión o el error están prioritariamente referidos a nuestras creencias y no al modo en que las cosas son o suceden. Este punto, creemos, entraña crucial relevancia para su filosofía práctica, puesto que la posibilidad de sobrellevar mejor la existencia dependerá en buena medida de nuestra superación de creencias erróneas -fundamentalmente, la de la posibilidad de una felicidad positiva-. Por lo antedicho, es factible afirmar que el pesimismo eudemonista no se funda en el carácter ilusorio de la felicidad per se. Lo

[44] Su idea, en efecto, de que algunos individuos alcanzan la salvación -por ejemplo los santos y los ascetas- presupone que éstos consiguen redimirse frente al dolor.

[45] Cf. MVR I, p. 405 (§56) / W I, 425.

Thémata. Revista de Filosofía No53 (2016) pp.: 141-160. 
ilusorio son las creencias que nos forjamos sobre ella y que proyectamos hacia el futuro.

Nos queda por examinar una última posibilidad: el pesimismo eudemonista se funda en el carácter negativo de la felicidad. Hay un pasaje digno de atención:

(...) la inalcanzabilidad de una satisfacción duradera y la negatividad de toda dicha, encuentra su explicación en lo que se mostraba como conclusión de la metafísica, a saber: que la voluntad, cuya objetivación es tanto la vida del hombre como cualquier fenómeno, es una tendencia sin objetivo ni final algunos. ${ }^{46}$

Este pasaje es muy interesante, dado que Schopenhauer explica apriorísticamente dos fenómenos característicos de la experiencia natural de la felicidad: su índole transitoria y su negatividad. Si bien ambas tesis se encuentran estrechamente entrelazadas, es posible señalar una distinción, dado que de ello se deriva a nuestro juicio un importante corolario. La negatividad del placer implica que éste puede tan sólo experimentarse como liberación de un dolor, en tanto que la aseveración conforme con la cual ninguna satisfacción duradera es posible, hace referencia al hecho de que la liberación del dolor no puede ser experimentada en forma perdurable. En nuestra opinión, es la última afirmación la que compromete más seriamente a Schopenhauer con el pesimismo antes que la tesis de la negatividad de la felicidad, como algunos afirman. ${ }^{47}$

La razón que ofrecemos para apoyar la conclusión precedente es la siguiente: si bien la negatividad de la felicidad es del todo compatible con la metafísica de la voluntad, no conlleva necesariamente pesimismo, por cuanto es una concepción que podría amoldarse también a una ontología «optimista». Este es el caso de Epicuro, quien igualmente defiende una visión negativa del placer pero que a diferencia de Schopenhauer, la sustenta sobre una ontología de sello opuesto, donde el carácter natural de la existencia se concibe como un orden intrínsecamente bueno. Para el primero, la disposición natural en la que originalmente se encuentra toda criatura es placentera y buena, precisamente por tratarse de un estado exento de dolor.

Si el razonamiento que acabamos de ofrecer es correcto, entonces habría buenas razones para creer que el pesimismo eudemonista de Schopenhauer está fundamentalmente referido a la imposibilidad de expe-

[46] MVR I, p. 417 (§58) / W I, 440.

[47] Por ejemplo Janaway le da un lugar preponderante a la cuestión de la negatividad de la felicidad en su interpretación del pesimismo schopenhaueriano. Cf. Janaway, C.: op. cit., pp. 331-332.

Thémata. Revista de Filosofía No53 (2016) pp.: 141-160. 
rimentar bienestar en forma duradera ${ }^{48}$, antes que en la tesis de la negatividad de la felicidad. Por tal razón, su filosofía práctica estará prioritariamente concernida con la cuestión de cómo conseguir sustraernos en forma perdurable, o medianamente constante, al dolor. Por supuesto que la negatividad de la felicidad desempeña también un rol central en aquélla, pero dado que a Schopenhauer le preocupa dar una respuesta a la pregunta de cómo vivir - tal como se afirmaba al comienzo de este artículo-, bregará por resolver la cuestión a partir de la demarcación de ciertas formas de vida donde llegaría a gozarse de una existencia apacible en forma estable.

\section{La fertilidad práctica del pesimismo}

Hemos mencionado antes que el pesimismo schopenhaueriano ha sido objeto de una variedad de interpretaciones, debido en buena parte a que Schopenhauer no avanza una teoría unificada del pesimismo ${ }^{49}$ y al hecho de que incurre en ciertas imprecisiones y contradicciones al intentar fundarlo, tal como hemos procurado mostrar. Sin embargo, hay un punto que puede servir para arrojar luz sobre el asunto: cada vez que el filósofo de la voluntad alude al pesimismo, suele contraponerlo al optimismo, de manera que es factible entender al primero como un término relacional o comparativo. Esto supone que el significado de "pesimismo» se vuelve mayormente comprensible al contrastárselo con el de «optimismo».

Es curioso que en sus obras publicadas Schopenhauer acostumbre emplear el concepto "pesimismo» para caracterizar doctrinas religiosas antes que filosóficas. Entre ellas sitúa al Cristianismo, el Brahmanismo y el Budismo $^{50}$, a las que contrapone la visión optimista figurada principalmente en religiones como el Judaísmo y el Islam. En su opinión, las últimas nos presentan el mundo como la obra de un ser supremo, y esgrimen la creencia de que la existencia está justificada por envolver valor intrínseco. El optimismo, con todo, consiste para Schopenhauer en un error que corta el camino a la verdad. ${ }^{51}$ En un pasaje impactante, asegura que si al más osado de los optimistas se lo llevara por hospitales y cárceles, por cámaras

[48] Esta imposibilidad se da más bien en el marco de la consciencia empírica y no en el de su trascendencia -la «mejor consciencia» o «negación de la voluntad» -. Es propio del primer modo de existencia, la afirmación de la voluntad, y en consecuencia, la afirmación del punto de vista hedonista. Pues para la consciencia natural, el bien supremo es la felicidad entendida como un estado de placer permanente.

[49] Cf. Atwell, J.: op.cit. p. 173.

[50] Su pesimismo radica en la apreciación de la existencia como un mal del que es preciso redimirse. Cf. MVR II, p. 611 / W II, 806.

[51] Cf. MVR II, p. 608 / W II, 803

Thémata. Revista de Filosofía №53 (2016) pp.: 141-160. 
de tortura o campos de batalla, se le volvería en cierto modo patente de qué naturaleza es el mundo que él cree ser "el mejor de los mundos posibles». ${ }^{52}$ En otras palabras, Schopenhauer cree que el optimismo es una doctrina errada por no reconocer a la existencia como un mal; adicionalmente, la considera una doctrina en cierto modo perversa, dado que subestima en el fondo al sufrimiento humano por creerlo justificado en función de un fin «superior».

Concomitantemente, nuestro autor cree incluso que el optimismo es una doctrina perniciosa desde un punto de vista práctico. Tras estipular como un error innato la creencia de que existimos para ser felices -un pasaje con el ya nos hemos familiarizado-, afirma:

Mientras sigamos aferrados a este error innato, corroborándolo mediante los dogmas optimistas, el mundo nos parece plagado de contradicciones. Pues a cada paso, tanto en lo grande como en lo pequeño, hemos de experimentar que el mundo y la vida no están preparados para albergar una existencia feliz. ${ }^{53}$

Estas líneas sugieren que el optimismo da pábulo a la creencia de que el mundo nos debe la felicidad, y por ende, que de la posibilidad de acople entre el curso de nuestros deseos y el del mundo, puede obtenerse una satisfacción genuina. Pero justamente por favorecer el optimismo dicha creencia, termina por infundir mayor frustración y descontento ${ }^{54}$ : las expectativas de felicidad positiva y permanente se ven luego traicionadas por la realidad de las cosas. De lo que se trata, por consiguiente, es de reconocer tal realidad; y a ese respecto, el pesimismo puede prestarnos un provechoso servicio al ilustrarnos sobre la naturaleza de ciertas cosas. Haciendo uso de una expresión de Janaway, el pesimismo posee un efecto educativo. ${ }^{55}$

El pesimismo eudemonista que hemos intentado reconstruir, nos enseña principalmente que por la vía de la satisfacción del deseo, no hay posibilidad de hallar gratificación permanente; asimismo, que dicha expectativa se genera por la propensión humana a depositar la felicidad en el futuro, como un estado al que se arribará al cumplirse el deseo, pese a lo cual termina por mostrarse como una simple quimera. En conexión con

[52] Cf. MVR I, p. 422 (§59) / W I, 445.

[53] MVR II, p. 616 / W II, 813-814. [El subrayado es nuestro]

[54] Exactamente en virtud de ello, Schopenhauer califica en otro pasaje al optimismo no sólo como una doctrina falsa, sino además funesta («nicht nur eine falsche, sondern auch eine verderbliche Lehre»). MVR II, p. 566 / W II, 748-749.

[55] Cf. Janaway, C.: op. cit., p. 324.

Thémata. Revista de Filosofía No53 (2016) pp.: 141-160. 
tales ideas se encuentra la tesis de la negatividad de la felicidad, la cual nos enseña que no podemos esperar obtener ningún goce positivo, sino tan solo la liberación de un dolor. Igualmente, y al tenerse muy en cuenta el sufrimiento como elemento esencial de la vida, el pesimismo nos alerta sobre la posibilidad de que nuestras metas se vean a menudo contrariadas y que en un mundo de tal índole, sea dable esperar cierta cuota de sufrimiento, incluso de gran sufrimiento. A pesar de que tales lecciones puedan parecer desalentadoras, poseen desde la óptica de Schopenhauer no sólo mayor verdad, sino también mayor potencial práctico que cualquier doctrina optimista puede proporcionar.

El efecto educativo del pesimismo trastocaría entonces ese conjunto de creencias ingenuas propias de la consciencia natural. ${ }^{56}$ En esta dirección, Schopenhauer nos invita a superarlas en base a su rectificación, consumada la cual cobra el mundo nueva luz: pues deja de verse desde el punto de vista de nuestros deseos para pasar a considerarse desde el punto de vista de su comprensión (Einsicht). ${ }^{57}$ También de manera significativa, el filósofo de la voluntad sostiene que de ser reconocido (erkannt) el dolor como aspecto consubstancial de la vida, ello podría conllevar una dosis de estoica serenidad. ${ }^{58}$ Con tales aseveraciones, se concede que esta suerte de comprensión metafísica es capaz de surtir poderosos efectos sobre nuestras vidas: si el mundo es un lugar del que no es dable esperar demasiado, entonces será mejor concentrarse en minimizar nuestras expectativas. La fertilidad práctica que esta idea contiene es manifiesta: la morigeración de nuestras aspiraciones es el arma más poderosa de la que disponemos para enfrentar el dolor. ${ }^{59}$ Paradójicamente, cuanto menos satisfacción se busca, mayor es la que se consigue: pues no existe bienestar mayor que el de la tranquilidad anímica, un estado donde la inquietud, el pesar o el descontento, colapsan.

\section{Consideraciones finales}

Hemos tratado de reconstruir hasta aquí el pesimismo eudemonista de Schopenhauer. Para ello fue necesario aludir a su metafísica de la voluntad y a sus implicancias antropológicas, asimismo a su concep-

[56] Estas creencias, las cuales encarnan un punto de vista hedonista y optimista, podrían sumariarse así: 1) la felicidad puede obtenerse como resultado de la satisfacción de nuestros deseos; 2) la felicidad es positiva y se identificaría con un estado de placer permanente; 3) el placer y la felicidad envuelven valores supremos; 4) el mundo nos debe la dicha.

[57] Cf. MVR II, pp. 617-618 / W II, 815.

[58] Cf. MVR I, pp. 411-412 (§57) / W I, 432.

[59] No por casualidad Schopenhauer erige en el corazón de su eudemonología una máxima que nos exhorta a evitar el dolor antes que a buscar el placer. Cf. PP I, p. 420 / W IV, 483.

Thémata. Revista de Filosofía No53 (2016) pp.: 141-160. 
ción negativa de felicidad. Hemos apuntado también algunos puntos endebles en la fundamentación schopenhaueriana del pesimismo, pese a lo cual puede reconfigurarse como una posición consistente. Aunque nuestro principal objetivo ha sido aquí el de evidenciar su potencialidad práctica. En nuestra opinión, la filosofía de Schopenhauer está atravesada por una preocupación cardinal: la cuestión práctica de cómo vivir. Siendo el mundo lo que es -un mundo pletórico de calamidad- esta cuestión se traduce en la de cómo hacer frente al dolor, y el pesimismo eudemonista nos alcanza una respuesta perfectamente sensible.

Para finalizar, quisiéramos retomar una reflexión hecha al comienzo: la actualidad del planteamiento de Schopenhauer y su potencial para contribuir a las discusiones contemporáneas enmarcadas principalmente en las éticas de la virtud. Pues de la mano de este enfoque se ha vuelto a poner en el centro de la escena la tematización filosófica de la felicidad y su conexión con la moralidad. Creemos que en este punto, el pesimismo eudemonista suministra una enseñanza firme y valiosa, justamente por sus efectos humanos: si las personas consiguieran moderar su querer, estarían contribuyendo a un mundo con menos dolor ${ }^{60}$, y esto, desde el punto de vista moral, no puede ser en absoluto irrelevante.

\section{Referencias Bibliográficas}

Atwell, John: Schopenhauer. The Human Character. Philadelphia: Temple University Press, 1990.

Else, Gerard: «Lucretius and the Aesthetic Attitude», en Harvard Studies in Classical Philology, Vol. 41, 1930, pp. 149-182.

Epicuro: Obras, estudio preliminar, traducción y notas de Montserrat Jufresa. Barcelona: Ediciones Altaya, 1998.

Fernandez, Jordi: "Schopenhauer's Pessimism», en Philosophy and Phenomenological Research, Vol. LXIII N ${ }^{\circ}$ 3, 2006, p. 646-664.

Janaway: «Schopenhauer's Pessimism», en C. Janaway (ed): The Cambridge Companion to Schopenhauer. Cambridge: Cambridge University Press, 2006, pp. 318-343.

Magee, Brian: Schopenhauer. Madrid: Cátedra, 1991.

Mann, Thomas: Schopenhauer, Nietzsche, Freud. Madrid: Alianza Editorial, 2000.

[60] Gran parte del padecimiento humano se origina según Schopenhauer en el conflicto que enfrenta a individuos egoístas, dispuestos a ocasionar sufrimiento a los demás con tal de cumplir sus propósitos. Luego es plausible pensar que un individuo con deseos moderados, al poseer menor avidez, estaría menos inclinado a disputar bienes a sus congéneres y a contender con ellos. 
Platón: La República, introducción, traducción y notas de José Manuel Pabón y Manuel Fernández-Galiano. Madrid: Alianza Editorial, 1988.

Schopenhauer, Arthur: Sämtliche Werke, Textkritisch bearbeitet und her ausgegeben von Wolfgang von Löhneysen. Stuttgart/Frankfurt am Main: Cotta-Insel (5 vols.), 1960/1965.

Schopenhauer, Arthur: El Mundo como Voluntad y Representación (Vol. I y II), traducción, introducción y notas de Roberto Aramayo. Madrid: FCE, 2005.

Schopenhauer, Arthur: Parerga y Paralipómena I, traducción, introducción y notas de Pilar López de Santa María. Madrid: Trotta, 2006.

Schopenhauer, Arthur: Parerga y Paralipómena II, traducción, introducción y notas de Pilar López de Santa María. Madrid: Trotta, 2009.

Simmel, Georg: Schopenhauer y Nietzsche. Buenos Aires: Prometeo, 2005.

Young, Julian: Schopenhauer. New York: Routledge, 2005. 